\title{
ADIAMENTO DO TREINAMENTO COLABORATIVO NOS TIPOS DE AVALIAÇÃO ${ }^{1}$
}

\author{
POSTPONEMENT OF COLLABORATIVE TRAINING IN THE TYPES OF \\ ASSESSMENT $^{1}$
}

Jairit Garavit ${ }^{2}$

https://orcid.org/0000-0003-1976-9891

1. ¿Este produto é o resultado do trabalho árduo de uma de suas Linhas de Pesquisa do projeto "Como deve pesquisar em Educação virtual e a distância?" do ano de 2021, realizada com Membros de forma interdisciplinar e interinstitucional (Professores - Alunos) da Pesquisa Seedbed: Sistemas Integrados de Gestão "Integradoss" Anexados ao GrupLAC: SIGCIENTY da Universidade Nacional Aberta e a Distância UNAD.

2. Engenheiro Industrial, Especialista em Educação Superior e à Distância, Mestre em Sistemas Integrados de Gestão HSEQ-RSC, Revisor de Pares da Elsevier, Revisor de Pares da Publons Academy e Advisor \& Peer Rewiever de Mendeley, Editor de Currículo em Revistas Acadêmicas - Minciencias. Líder da Seedbed de Pesquisa "Integradoss" e nomeado Professor Pesquisador da Escola de Ciências Básicas, Tecnologias e Engenharia ECBTI. Zona Caribenha, na Universidade Nacional Aberta e a Distância - UNAD. Email institucional Jairit.Garavit@unad.edu.co

Projeto de Pesquisa: ¿Cómo pesquisar em Educação virtual e a distância? 
Resumo: A aprendizagem profunda requer raciocínio e comunicação do pensamento através da discussão, escrita, atuação e demonstração da eficácia da aprendizagem e avaliação horizontal, ou seja, de aluno para aluno. Obviamente, a formação colaborativa é uma abordagem de interesse em faculdades e universidades, uma vez que permite aos alunos aprofundar a aprendizagem através do intercâmbio entre pares. Para o benefício dos colegas que desejam adotar esta abordagem ou revisar seus fundamentos, reunimos aqui os principais elementos da formação colaborativa, bem como as limitações associadas ao ensinoaprendizagem. Porém, Podemos avaliar o papel da ferramenta no trabalho colaborativo realizado por meio de uma intranet educacional? Esta comunicação tem como objetivo examinar como a ferramenta estrutura as interações e auxilia no desenvolvimento de um treinamento coletivo. Podemos definir marcos que nos permitem medir essa contribuição da ferramenta? A nossa análise baseia-se numa dupla metodologia de observação a posteriori da actividade dos alunos na utilização da ferramenta (análise de traços) e entrevistas com os grupos e o tutor ou professor. Podemos definir marcos que nos permitem medir essa contribuição da ferramenta? A nossa análise baseia-se numa dupla metodologia de observação a posteriori da actividade dos alunos na utilização da ferramenta (análise de traços) e entrevistas com os grupos e o tutor ou professor. Podemos definir marcos que nos permitem medir essa contribuição da ferramenta? A nossa análise baseia-se numa dupla metodologia de observação a posteriori da actividade dos alunos na utilização da ferramenta (análise de traços) e entrevistas com os grupos e o tutor ou professor.

Palavras chave: Treinamento colaborativo, intranet educacional, uso das TIC, avaliação.

Abstract: Deep learning requires thinking and communication of thought through discussion, writing, acting and demonstrating the effectiveness of learning and horizontal evaluation, that is, from student to student. Obviously, collaborative training is an approach of interest in colleges and universities, since it allows students to deepen their learning through exchanges between peers. For the benefit, colleagues who wish to adopt this approach or revise its foundations, we have gathered here the main elements of collaborative movement as well as the limitations associated with teaching learning. However, can we assess the role of the tool in collaborative work carried out through an educational intranet? This communication aims to examine how the tool structures interactions and assists in the development of a collective training. Can we define milestones that allow us to measure this contribution of the tool? Our analysis is based on a double methodology of a posteriori observation of the activity of the students in their use of the tool (trace analysis) and interviews with the groups and the tutor or teacher.

Keywords: Collaborative training, Educational intranet, Uses of ICT, Evaluation. 


\section{Introdução}

O reconhecimento da dimensão coletiva do trabalho e a importância de se pensar transversalmente nas organizações levam as instituições formadoras a introduzirem o trabalho em grupo na graduação. Da mesma forma, as tecnologias de comunicação permitem agora a concretização desta atividade coletiva, seja através de trocas e coordenação de pessoas à distância ou presencial. Como Cardon (1997) observou há algum tempo em uma apresentação já antiga dos dispositivos incluídos no treinamento colaborativo assistido por computador (FCAC), essas máquinas de comunicação não se contentam mais em facilitar as trocas entre pessoas distantes, mas prometem criar espaços de comunicação. trabalho comum. É possível compartilhar aplicativos, trocar documentos animados ou sonoros, escrever no mesmo texto, coordenar agendas. A hipótese subjacente é que esses espaços comuns promovem, ou mesmo desempenham um papel ativo, na realização do trabalho coletivo.

¿Más e quanto à apropriação dessas ferramentas pelos alunos para trabalhar e produzir juntos em uma situação? Aprendendo? Podemos avaliar o trabalho colaborativo em termos de uso da ferramenta?

Nesta comunicação daremos algumas respostas, à luz de situações de trabalho coletivo com recurso a uma ferramenta de trabalho colaborativo, apoiando-se nas falas dos atores principais, os alunos, e na análise dos vestígios da sua atividade na ferramenta.

\section{Ilustrações}

¿O que entendemos por treinamento colaborativo ou trabalho colaborativo? Essas noções merecem uma discussão mais aprofundada, pois resultaram em uma literatura abundante, com foco em particular na distinção entre cooperativo e colaborativo. Se Dillenbourg (1999) realizou uma pesquisa, em uma revisão da literatura, que colaboração e cooperação são algumas vezes usadas como sinônimos, ele especifica que alguns pesquisadores baseiam a diferença entre as duas noções no grau de divisão do trabalho.

Em uma situação cooperativa, a divisão do trabalho é maior: as subtarefas são executadas individualmente e frequentemente de forma assíncrona e, em seguida, os resultados desse trabalho são reunidos em um produto final. Já uma situação colaborativa é mais frequentemente caracterizada por interações sincrônicas durante as quais os indivíduos realizam o trabalho que devem realizar juntos.

Jermann e Dillenbourg (1999) eles também especificaram que a noção de coletivo difere daquela de colaborativo no sentido de que não implica necessariamente interações ricas entre 
os alunos. É o sistema que então coleta as produções individuais e as disponibiliza a todos. Nesse mesmo artigo, os autores questionam o papel dos pontos de vista divergentes, mostrando que é mais a verbalização gerada para resolver as diferenças que participa da aprendizagem.

Smith (citado por Jermann e Dillenbourg, 1999) desenvolveu uma tipologia de conhecimento baseada na persistência da visualização de um conhecimento (por quanto tempo um conhecimento pode ser visível em um meio). Este elemento parece-nos particularmente interessante notar quando se passa por uma mediação que, ao contrário das trocas de e-mail, permite uma certa permanência dos documentos no espaço público. Vários autores (Baker, Hansen, Joiner e Tream, em Dillenbourg, 1999, Leplat, 1991) sublinham a importância de uma base comum (como sugerido pela noção de terreno comum, ou novamente, em outro domínio, de referência comum) que se desenvolve nas interações, e que todos devem manter para alcançar um trabalho comum. A partir da ideia de uma referência comum pré-existente necessária ao grupo,

Nos casos que estamos estudando, a distinção entre cooperação e colaboração nem sempre é óbvia: os grupos preferem trabalhar para desenvolver em conjunto uma solução negociada e consensual, que é o trabalho colaborativo. Mas também são levados à partilha de tarefas entre os diferentes participantes e a colocar em comum, a posteriori, por justaposição das contribuições de cada um, o que caracteriza o trabalho cooperativo.

¿Por fim, e quanto à oposição entre treinamento e trabalho colaborativo? No âmbito de uma formação, o objetivo é a aprendizagem e colaboração de uma modalidade de aprendizagem entre outras, confrontando o pensamento da outra e os esclarecimentos necessários que isso implica na interação. Mas no contexto de uma formação-ação orientada para o desenvolvimento de competências profissionais através de uma ordem real, não estaremos na fronteira entre a formação colaborativa e o trabalho colaborativo? Não sendo o propósito desta comunicação alimentar esta problemática complexa, optamos pela comodidade de adotar a expressão trabalho colaborativo em situação de aprendizagem.

Além da terminologia, parece-nos importante tentar caracterizar este treinamento colaborativo. Em outras palavras, o que permite a um grupo atingir uma produção comum? A partir da observação de grupos que atuam exclusivamente a distância, (Deaudelin, 2003) percebe a colaboração como uma situação de aprendizagem na modalidade virtual e que possui três componentes principais: compromisso com o grupo, comunicação, coordenação.

No que diz respeito, no contexto dos grupos que temos observado, e vamos manter o seguinte: 
- Coordenação: distribuição de funções e tarefas, organização (gestão de contatos, prazos, etc.).

- Comunicação dentro do grupo e com atores externos.

- Capacidade de produção coletiva (co-escrita de documentos, envolvendo confronto de pontos de vista e negociação).

Em particular, examinaremos a estruturação do grupo, que se baseia nesses três componentes. A partir daí, vamos nos concentrar no papel que a ferramenta de treinamento colaborativo desempenha nessas diferentes manifestações de trabalho conjunto. Examinaremos como a ferramenta estrutura ou não as interações até que ela contribua, se necessário, para o desenvolvimento de um treinamento coletivo. (Grosjean e Lacoste, 1999).

¿Dados quantitativos, como o número de contribuições ou o grau de estruturação dos espaços, podem ser relevantes para dar conta da formação colaborativa? Note-se que o que aqui se estuda não é a característica do trabalho derivado do grupo (cuja interpretação final resulta numa classificação por um júri no âmbito de uma avaliação sumativa) mas antes as manifestações do trabalho. colaborativo.

\section{Figurações e hipóteses}

Isso nos leva a formular a seguinte hipótese, que as entrevistas permitirão invalidar, confirmar ou qualificar: os grupos que muito utilizaram a ferramenta de formação colaborativa e que estruturaram seu espaço são aqueles que fazem parte de uma colaboração ativa e fecunda, quer em termos de coordenação, comunicação e produção. Por exemplo, esses grupos terão utilizado todas as funcionalidades da ferramenta, depositado um grande número de documentos no espaço compartilhado, tudo resultando em um grande número de contribuições com base no maior número possível de colaboradores dentro do grupo.

Eles também terão estruturado o espaço de trabalho compartilhado criando diretórios; eles terão normalizado seus nomes de arquivo. Se esta hipótese se baseia na correlação entre o uso da ferramenta de treinamento colaborativo e a colaboração no grupo, obviamente não se trata de aderir a uma visão determinística onde a ferramenta por si só induziria ao funcionamento do grupo. Em vez disso, tentaremos medir com precisão como o grupo usa a ferramenta para realizar seu treinamento colaborativo, embora esta não seja uma etapa necessária, uma vez que os grupos costumam estar presentes e que o uso da ferramenta não é um imperativo nessas aulas.

Além disso, enquanto não se trata de uma obra coletiva em andamento, é a coleção de vestígios dessa atividade que será para nós um indício de uma atividade coletiva a posteriori. 
Mas estamos bem cientes de que a atividade coletiva ocorre em vários ambientes, sendo o mais comum, sem dúvida, o encontro face a face dos membros da equipe.

\section{Domínios espaciais}

Para confirmar ou refutar essas hipóteses, escolhemos como campo dois cursos de formação distintos, oferecidos no curso de formação de alunos da Escola (Faculdade) de Engenharia Industrial da Universidade Nacional Aberta e a Distância - UNAD. Estes treinamentos (seminário aprofundado), que ocorrem em medidas normais durante um período de seis meses, (duas vezes por ano) são realizados todos os anos de janeiro a julho e de agosto a dezembro, optamos por estudar o que ocorreu no primeiro semestre de 2020 .

Um deles é o treinamento em gerenciamento de projetos com base em um pedido real. É uma ação-formação, na qual participam diferentes atores: a equipa do projeto (um grupo de quatro a cinco alunos), o patrocinador (um estabelecimento externo que propõe que o aluno explore o projeto) e o tutor (um membro do corpo docente equipa) responsável pelo apoio ao grupo de alunos. Este treinamento é baseado em uma forte estrutura institucional: uma distribuição de funções dentro da equipe, um forte cronograma definido pelos comitês de gestão, um processo de validação pelo tutor de determinados documentos discutidos no comitê de gestão.

O outro é o treinamento em pesquisa baseado em comissão proposto por um diretor de pesquisa que supervisiona o trabalho de um grupo de dois a cinco alunos (estágio interno a universidade externa). A estrutura institucional aqui é bem menos forte, a única restrição é a data de envio do documento final. Uma ferramenta de treinamento colaborativo, embutida na intranet educacional, é oferecida como suporte a esses dois módulos de treinamento. Acessível remotamente na autenticação (usuários e senha), inclui várias funções:

- Bibliotecas de documentos compartilhados (comuns ao grupo e ao diretor de pesquisa no âmbito do módulo de pesquisa; separadas no âmbito do projeto em três espaços de trabalho diferentes: um reservado para a equipe; o outro compartilhado com o tutor; o último compartilhado com o patrocinador).

- Um fórum dedicado às relações entre o grupo e o diretor ou orientador da pesquisa.

- Gerenciamento de contatos e gerenciamento de tarefas.

- Uma funcionalidade de fluxo de trabalho, como parte do treinamento em gerenciamento de projetos, que permite que apenas os documentos validados pelo tutor fiquem visíveis para o patrocinador. Todos os grupos normalmente precisam passar por esse procedimento, o que significa uso mínimo da ferramenta. 


\section{Métodos de assimilação}

Depois de ter realizado uma identificação inicial dos espaços colaborativos de todos os grupos, selecionamos uma amostra de sete grupos, escolhidos por seu uso contrastante da ferramenta de trabalho colaborativo: grandes usuários sentam-se lado a lado com usuários médios e não usuários.

Para cada um desses sete grupos, tentamos reconstruir a posteriori a atividade dos alunos no uso da ferramenta por meio de uma análise quantitativa:

- Uso do fórum; número de contribuições; número de contribuintes; parte das contribuições dos tutores.

- Uso de espaço de documento compartilhado; número de documentos arquivados; número de contribuintes.

- Uso da funcionalidade de contatos; número de contribuições; número de contribuintes.

- Uso da funcionalidade de tarefas; número de contribuições; número de contribuintes.

Também tentamos medir o grau de estruturação do espaço:

- Número de diretórios criados; profundidade da árvore; taxa de estruturação (número de arquivos / número de diretórios).

- Padronização da nomenclatura de arquivos.

Comparamos esta observação com duas séries de entrevistas, uma com o tutor; a outra com o grupo (mais ou menos completa por motivo de disponibilidade do aluno). No total, entrevistamos 16 alunos e 6 tutores.

A entrevista com os alunos incidiu sobre os métodos de trabalho dentro do grupo e sobre a parte que a ferramenta de formação colaborativa proposta pela instituição poderia ter assumido neste trabalho em equipa, sem descurar as outras ferramentas que possam ter sido utilizadas. Para trabalhos comuns (telefone, clássico ou mensagens instantâneas, blog). Por fim, para todos os grupos que utilizaram a ferramenta de trabalho colaborativo, ao final da entrevista propomos um confronto com o seu espaço, a fim de aprofundar o discurso coletado.

O objetivo da entrevista com o tutor foi obter a sua avaliação sobre o trabalho colaborativo realizado pelo grupo e tentar estimar o papel que ele próprio tem vindo a desempenhar na sua organização e estruturação. Portanto, é uma mistura dos dois pontos de vista (grupo e tutor) que nos permitiu apreciar o funcionamento do grupo. 
Realizamos essas entrevistas em duplas e têm duração média de uma hora (30min). Sendo respectivamente responsáveis pelo treinamento em gerenciamento de projetos e responsáveis pelo serviço de TIC, nosso registro institucional pode constituir um viés que tentamos limitar por meio de nosso protocolo de pesquisa.

\section{Componentes externos}

Nessa complexa relação que se estabelece entre colaboração e ferramenta, identificamos uma série de fatores que influenciam significativamente na decisão do grupo de usar ou não a ferramenta.

O primeiro é o da apropriação. Na verdade, é importante observar que os alunos iniciam esses relatórios ou módulos colaborativos (Unidades) quando chegam à instituição. Todos são treinados na ferramenta, mas para a maioria é uma descoberta. Alguns, portanto, encontram dificuldades de apropriação; Outros apresentam limitações de acesso: aqueles que não possuem computador conectado à Internet e que, portanto, só podem utilizar a ferramenta dentro das dependências da instituição. Finalmente, outros enfrentam obstáculos técnicos relacionados a problemas de compatibilidade ou limites de ferramentas. Essas dificuldades, que podem parecer cíclicas, na verdade têm um impacto significativo na decisão do grupo de usar ou não a ferramenta de treinamento colaborativo.

Os demais stakeholders do projeto também têm uma forte influência: se o tutor e o patrocinador (para o projeto) ou o diretor de pesquisa (para a pesquisa) usam a ferramenta de formação colaborativa como um local privilegiado para seus intercâmbios com o grupo na extensão.

Em tempos face a face, se eles têm um discurso pró-ativo diante da ferramenta, é óbvio que isso constitui pelo menos inicialmente um forte incentivo para superar as primeiras relutâncias ou dificuldades. A diferença entre as duas formações também é bastante significativa do ponto de vista dos instrumentos utilizados. Inseridos em grupos maiores (em média 5 pessoas por grupo em vez de 3), num quadro educacional mais estruturado e supervisionados por mais equipas pedagógicas intervenientes, os alunos utilizaram a ferramenta mais no contexto do projeto do que no contexto da investigação, ainda que eles eram os mesmos alunos.

Todos esses fatores externos referem-se ao conceito de aceitabilidade introduzido por Tricot (2003). A partir de uma hipótese, a análise de uso em relação aos temas discutidos é reveladora: como o tema inclui uma componente tecnológica e vinculada ao tema da troca de informações, fica evidente o suporte para a ferramenta, o que foi muito bem expresso pelo 
tutor de um. da maioria dos usuários: Como poderia ser estabelecido em um sistema de informação, trabalho colaborativo, e isso faz parte do espírito do projeto, o tema induziu seu uso.

\section{Análise do funcionamento do grupo}

Entre os sete grupos estudados, podemos distinguir três níveis de uso:

- Usuários fracos (quatro grupos: projetos e pesquisas) que não usaram a ferramenta ou pouco - menos de 100 contribuições 4 no total

- Usuários médios (um grupo de pesquisa) que fizeram uso moderado - entre 100 e 200 contribuições.

- Usuários intensivos (dois grupos de projetos) que utilizaram muito a ferramenta mais de 200 contribuições.

Portanto, tentaremos relacionar esse uso ao funcionamento do grupo, visto com uma lupa a partir dos três componentes do trabalho colaborativo: coordenação, comunicação, produção coletiva.

\section{Coordenação e uso da ferramenta}

¿A ferramenta é um ótimo teste piloto? Você permite que o grupo se organize? Esse agrupamento de tarefas e prazos na ferramenta difere de acordo com a organização do grupo?

\section{Uma perspectiva que não aparece}

Os usuários fracos em geral deixaram poucos vestígios de suas ações de coordenação na ferramenta. As funções de tarefas não são usadas; Contatos; Eventos ", o que poderia refletir o estabelecimento de uma divisão de tarefas e de uma organização. Também não há estruturação do espaço de trabalho: em número reduzido, os documentos depositados não são classificados em diretórios e seus nomes não são padronizados.

¿Por outro lado, o que as entrevistas nos dizem sobre a organização do grupo? Em um deles, o grupo se diz bem organizado, mas essa organização é pouco formalizada, isso não parece atrapalhar o funcionamento, já que o grupo é pequeno (3 pessoas), o tutor está muito presente e a face as reuniões presenciais são agendadas semanalmente. A coordenação provavelmente ocorrerá cara a cara graças a essas reuniões regulares.

Em dois outros grupos, encontramos essa falta de explicação da organização: o grupo segue a distribuição de papéis conforme definido no contexto de gerenciamento de projetos: 
Queríamos seguir o modelo proposto. Além disso, não há memória clara: não sei mais, que era informal, a maior parte foi feito juntos. Esses dois grupos parecem ter funcionado bem, mas nada mais. A convivência dificilmente se expressa e não se pode dizer que exista um verdadeiro clima de cooperação. O coletivo é percebido inicialmente como um obstáculo a ser superado - um dos integrantes também destaca a dificuldade de organizar o espaço comum: No meu computador pessoal estava mais bem organizado do que isso, por temas e por fases de projeto.

Porém, se o grupo usa muito pouco a ferramenta a serviço da coordenação, sabe depois que seu uso poderia ter possibilitado a organização coletiva do trabalho: O compartilhamento por e-mail funcionou muito bem. Mas a organização, talvez tematicamente e na nossa cabeça, as coisas teriam ficado ainda mais expostas no mesmo espaço. Visualmente, na organização do grupo mesmo, mas na visualização, sensibilização, distribuição dos diferentes trabalhos, dá uma visão geral da evolução do trabalho que não aparece ou menos por email. A função de visibilidade para todos, num espaço comum, da distribuição das tarefas e do andamento dos trabalhos é percebida como uma função possível da ferramenta, mas que requer, como pré-requisito, a escolha: deliberação coletiva.

\section{Coordenação através da ferramenta}

Como contraponto, o quarto grupo, que está entre os usuários mais fracos, adotou uma estrutura bastante extensa em arquivos e subarquivos. A taxa de estruturação5 está claramente acima da média e a estrutura em árvore é bastante desenvolvida: alguns diretórios possuem apenas um arquivo (com o mesmo nome do diretório). Nos encontramos aquí en el caso ligeramente diferente de un grupo que tenía el deseo de establecer una organización y coordinación sólidas, pero cuyo espacio común no fue realmente invertido por todos, lo que da como resultado un pequeño número de contribuyentes, así como de documentos a a vista. da hiperestruturação posta em prática.

A entrevista confirma o envolvimento significativo de uma pessoa muito militante na ferramenta, talvez em descompasso com o resto do grupo. Segundo o tutor, o investimento foi muito desigual. Isso mostra que a função de coordenação por meio da ferramenta não pode ser decretada, e que deve resultar de um consenso profundo ao longo do trabalho.

Nos outros três grupos (usuários médios e pesados), os traços de coordenação são claramente visíveis na ferramenta. Existe uma grande coerência entre a observação dos espaços e as entrevistas realizadas com os grupos: o espaço comum testemunha, assim como os alunos, os métodos de organização adoptados e o bom funcionamento dos grupos, com total disponibilidade para o uso. as ferramentas. 
Equilíbrios com evidente pragmatismo: se são utilizadas as funcionalidades propostas, são utilizadas para satisfazer uma necessidade real, quer no início da formação, quando o grupo se estrutura, quer num momento preciso em que a proximidade de um termo se impõe por exemplo para distribuir com precisão as tarefas como parte de uma única ação. Isso pode levar ao abandono da função quando ela não for mais necessária, para negociar novas funcionalidades (diário de bordo, por exemplo); ou utilizar ferramentas externas (em particular, uma ferramenta gratuita de produção de gráficos de Gantt que permite destacar a programação e distribuição das tarefas no espaço, etc.).

Estruturar espaços de trabalho comuns é muito revelador para uma organização. O princípio é que colocamos tudo no espaço, pelo menos tínhamos a certeza de que estava lá. A partir de uma decisão conjunta de depositar sistematicamente, os arquivos, que muitas vezes correspondem a uma nomenclatura padronizada, são classificados em diretórios, com uma estrutura em árvore que todos podem fazer seus próprios. Essa ação no espaço permite que o grupo se oriente e deve facilitar o trabalho coletivo nos documentos.

Nos três grupos a limpeza era feita por um responsável por essa função, muitas vezes de forma tácita, é verdade que essa ideia partiu de mim, e é mais fácil encontrar, fruto de um acordo implícito, esses rearranjos obedecem, não No entanto, para uma análise sutil da situação: um desses arquivistas explica, por exemplo, que deixou os documentos em massa no início, para que fiquem visíveis na página inicial, e depois os colocou na árvore de estrutura assim que já não tínhamos este estado atual: quando terminamos arquivamos. É inofensiva, à primeira vista, esta classificação função, e claramente põe em jogo a questão da confiança, aliás estamos dentro de um território comum, e poder reivindicar o direito de modificar sua disposição,

\section{Comunicação e uso da ferramenta}

O objetivo aqui é estudar como os grupos se comunicavam entre si e com atores externos, por meio ou fora da ferramenta. As trocas são principalmente uma prerrogativa face a face? A ferramenta é um lugar de expressão? Um fator de facilidade de uso? A apresentação de documentos também não é um ato de comunicação? A produção de documentos comuns é apoiada por trabalhos de esclarecimento? Isso é visível na ferramenta? É importante especificar nesta fase que os alunos não têm um fórum de discussão reservado para o grupo dentro da ferramenta. Como resultado, as trocas internas necessariamente escapam à ferramenta e, naturalmente, referem-se a face a face ou e-mail. Com certeza,

O fórum, por sua vez destinado a acolher discussões com o orientador ou diretor de pesquisa, adquire, portanto, um caráter mais institucional. Não entraremos em uma análise detalhada da relação do tutorial aqui por meio da ferramenta. (Peyrelong, Follet, 2004), mas 
é óbvio que isso é muito mais investido pelo grupo que tem várias razões para fazê-lo. Se o mentor e o patrocinador forem amadores, isso pode criar um efeito cascata, até mesmo massa crítica. Concebidos para serem uma encruzilhada entre o trabalho do grupo e as relações com o tutor e o diretor de pesquisa, sem esquecer o patrocinador, os espaços cumprem, assim, múltiplas funções. Como os grupos percebem a revisão do indicador de comunicação?

Para os três grupos de usuários fracos, a ferramenta é bem percebida como um local de troca de documentos dentro do grupo, mas não resiste à concorrência do e-mail: dispensando a leitura de anotações, é mais prático pelo correio. A ferramenta parece um warehouse, um repositório: a função estática tem precedência sobre a função de circulação. É preciso dizer que, para nenhum desses três grupos, o tutor ou diretor de pesquisa fez uso da ferramenta.

\section{Segmentos anexados}

Ponto de vista radicalmente diferente para o quarto grupo: convencido de que a ferramenta pode desempenhar um papel na capitalização de trocas, um dos membros do grupo tenta configurar o fórum como um local de comunicação com o tutor, mas a mensagem é, em última instância, instância adotada, uma A pasta de correspondência é criada contendo cópias dos e-mails mais importantes. O telefone é proibido quando se trata de falar de conteúdo, pois é uma fonte de perdas em relação a essa perspectiva de acompanhar o trabalho

A entrevista também vai levar a um lapso muito revelador: evocando o envio de peças anexas por correio, a entrevistada disse: Ela mandou tudo em peças sobressalentes. Então, percebendo seu erro, comenta assim: Em algum lugar separamos o e-mail do conteúdo anexado e retiramos o material do que estava dizendo, a seguir colocamos de volta no espaço e conversamos sobre isso juntos.

Essa tensão entre comunicação e preservação, entre circulação e armazenamento de informação, é evocada por diversos grupos, em especial os usuários pesados, que buscam constantemente ajustar o uso das ferramentas às suas necessidades. Um deles destaca a importância da função de alerta, uma espécie de link entre o espaço de arquivo de documentos e o e-mail (a ferramenta permite agendar um e-mail automático notificando cada novo depósito de documento no espaço). Esse recurso, que permite receber sinais da atividade de outros membros em tempo real, é considerado muito importante para aproximar o grupo: eles se mobilizam para contribuir; é bom para o moral, vemos as coisas se moverem.

No entanto, a ferramenta não é percebida como um fator de facilidade de uso: ela desempenhou um papel na comunicação, mas a facilidade de uso é um pouco forte, não nos serve café, e curiosamente, porém, um grupo deu à ferramenta um apelido como animal de estimação: era uma piada particular. O que não é necessariamente um sinal de aceitação (pode 
ser uma piada), mas mostra que a ferramenta faz parte da vida do grupo. Um elemento que se encontra para os outros e que atestam certos desvios da ferramenta ao serviço do reforço da coesão (a utilização da função - tarefas para relançar um colega de forma humorística, por exemplo). Porém,

Um afirmando: Era o lugar institucional de diálogo com o tutor e o patrocinador. O outro enfatizando sua importância: Se não o tivéssemos, acho que teríamos encontrado outra ferramenta. Do contrário, não teríamos saído com a imagem negativa que ela incorpora através da sua inscrição institucional: Estávamos reclamando da ferramenta, o lado da obrigação pesa. O que também levou esse grupo a se apropriar paralelamente de uma ferramenta de blog, não marcada com o selo da instituição: Foi uma espécie de saída.

\section{Produção coletiva no uso da ferramenta}

Nesta parte, não nos interessa o sentido estrito do processo de escrita coletiva, que é melhor compreendido e analisado por meio de observações etnometodológicas da escrita em andamento, como Miecznikowski e Mondada fizeram em Gaulmyn, Bouchard e Rabatel (2001). O que nos interessa aqui são os vestígios dessas múltiplas produções (documentos finalizados, documentos intermediários em várias fases de finalização e que ainda trazem as marcas de autores e revisores sucessivos). O que a ferramenta e os grupos nos dizem sobre sua capacidade de desenvolver documentos coletivamente?

Em geral, escrever é visto mais como um ato individual, baseado em uma tarefa de casa. Existem alguns momentos de escrita verdadeiramente colaborativa (simultaneamente na mesma tela). O que muda são as maneiras como os grupos gerenciam as diferentes contribuições sucessivas para constituir um documento comum. $\mathrm{O}$ desenvolvimento geral é feito de forma gradual, comparando essas entradas individuais, onde e quando elas tiveram que ser corrigidas, muitas vezes corrigimos juntos a partir das versões em papel.

As explicações e provavelmente as negociações são feitas cara a cara: ¿você quis dizer o quê? Esse processo de correção via discussão é citado como um dos motivos para a não utilização do espaço colaborativo: Não teria sido útil porque estávamos discutindo antes de corrigir o documento, precisávamos de explicações verbais. Essa relutância em utilizar o espaço compartilhado também está ligada ao desejo de respeitar a caligrafia dos demais membros da equipe: não nos sentimos autorizados a corrigir a parte alheia, a possibilidade de retrabalhar diretamente os documentos depositados no espaço não entra nas representações . Por outro lado, arquivá-los permite que você os leia antes de uma reunião de revisão para torná-la mais produtiva. 
Invoca-se também a ideia de número: ¿por qué passar pela mediação se a produção de documentos pode ser bastante gerenciável em um grupo de 3 pessoas? Para outro grupo de usuários fracos, a produção de um documento envolve a distribuição dos escritos e depois a revisão por todo o grupo: todos corrigiam quase tudo, as revisões eram individuais, então, após o compartilhamento, o documento era revisado na íntegra. Este processo de preparação conjunta de documentos é fruto de uma aprendizagem: o grupo desenvolveu assim uma capacidade de crítica mútua: todos têm o direito de ver tudo.

\section{Uma boa ferramenta de colaboração, o gerente de projeto}

Se a negociação é de fato um elemento na constituição da aprendizagem coletiva, ela não pode ser decretada e o espaço para tanto deve ser construído. Os elementos são então integrados em um documento mestre pelo gerente de projeto que desempenhou o papel de ferramenta de trabalho colaborativo. Portanto, atribuímos ao espaço uma capacidade de integração, ainda que, de fato, poucos documentos tenham sido depositados nele, e se perceba que ele não desempenhou um papel na produção. $O$ trabalho de integração pressupõe competências que obviamente uma ferramenta não possui, pois se trata precisamente de referir-se a uma inteligibilidade do documento elaborado e, portanto, de intervir no conteúdo, alisando, valorizando a coesão. No entanto, esta representação é bastante interessante de notar,

\section{Compromisso do grupo com o avanço}

Em outro grupo, há partes de documentos no espaço, mas muitos parecem ter sido depositados a posteriori, ou mesmo re-depositados várias vezes no mesmo espaço. Portanto, os documentos não estão lá para serem retrabalhados, aqui novamente, depois de algumas tentativas de escrita multimanual, o processo é dividir o documento a ser produzido em partes e, em seguida, agrupá-lo.

Neste grupo, a procura do compromisso é vista como um imperativo essencial face à obrigação de resultado, mas em detrimento da qualidade: Quando olhamos para uma questão por conta própria, tendemos a aprofundar mesmo, para que quando o façamos estão todos juntos, no final buscamos mais compromisso do que progresso e aprofundamento. O coletivo, portanto, parece ser vivenciado como uma perda. A natureza técnica do assunto, sem dúvida, também levou o grupo a criticar mais a forma do que a substância. Os poucos documentos

publicados no espaço comum são explicados novamente pelo fato de que o documento realmente precisava ser mais finalizado, e tivemos que nos certificar de que este documento fosse mantido ali. A ferramenta parece um lugar onde não havia razão para mudá-la, 
O último grupo de usuários fracos usou a ferramenta como um espaço de trabalho - o trabalho é feito em casa e depois colocado na ferramenta. $\mathrm{O}$ trabalho é realizado em paralelo em diferentes partes, extraindo os documentos do dispositivo e colorindo as modificações. Embora este grupo seja considerado um usuário fraco, este parece ter participado, ao tornálos visíveis e discutir documentos, de uma produção coletiva. Os membros desse grupo trabalham em pares de variáveis de acordo com relações de significado de uma parte da investigação para outra. Em seguida, o e-mail é utilizado para a metacomunicação sobre o texto (informações sobre as modificações realizadas, explique um pouco o caminho).

\section{Versões próprias da ferramenta}

Se tomarmos agora o grupo que se enquadra na categoria de usuários médios, a ferramenta foi inicialmente $\mathrm{o}$ ator na elaboração dos documentos. O desejo inicial era ter um documento comum no espaço colaborativo, mas as dificuldades em particular na gestão das diferentes versões do documento, fizeram com que o grupo adotasse regras de produção para trabalhar em conjunto no mesmo documento e contornar o problema: Fizemos versionamento com nosso próprio molho, atribuindo cores. Aqui novamente encontramos o uso do e-mail como uma metacomunicação: Atenção, não toque, estou levando os documentos comigo, mas também para discutir o conteúdo. Neste grupo não houve escrita coletiva, daí a necessidade de visibilidade. Sim portanto

\section{Documentos imutáveis}

Os usuários regulares também não praticam a digitação com várias mãos. Para os integrantes de um dos dois grupos, o espaço desempenha o papel de uma biblioteca de arquivos, permitindo que a gênese do desenvolvimento seja reconstruída em forma de anotações ou destaques em cores diferentes. As partes dos textos são redigidas individualmente e alisadas no documento final. A entrevista nos ensina que os documentos são objeto de negociação bipartidária, e não são depositados na ferramenta para discussão geral antes da validação pelo par: Para que um documento fosse apresentado, ele precisava ser visto por duas pessoas. Foi um acordo implícito. Este é um dos poucos grupos em que o trabalho editorial (Guyot e Peyrelong, 2005) se destaca de forma tão explícita.

É interessante que possamos, com a mesma ferramenta, assumir posições tão diferentes. Todos os documentos visíveis no espaço são documentos de produção (documentos que mostram as diferentes etapas, depois o documento final), mesmo que o espaço ainda seja percebido como uma biblioteca de arquivos. Não é o local de trabalho em andamento, mas o favorece. Como a informação circula com bastante antecedência, chegamos a uma reunião dando um passo para trás. O documento está escrito a frio. No entanto, a ferramenta ainda é o local onde esses documentos frios são mantidos em face das fases de preparação, a 
negociação presencial. A forte estruturação do grupo e a sua coesão refletem-se na sua produção (e nos rastros que deixou na ferramenta).

\section{conclusão}

\section{Volte para a hipótese}

Ao final desta análise, podemos dizer que os grupos que mais utilizaram a ferramenta de trabalho colaborativo mostraram uma colaboração ativa e fecunda? Em relação aos três componentes analisados, responderíamos afirmativamente: de fato, os grupos que mais utilizaram a ferramenta apresentaram um grande número de contribuições e aproveitando todas as suas funcionalidades são aqueles que atestam, por meio de entrevistas, bons resultados. coordenação em equipe, comunicação ativa e boa capacidade de produção coletiva.

O fato de haver dois grupos de projetos nesta categoria de usuários fortes, para os quais o uso da ferramenta é mais fortemente induzido, não parece ter influenciado, uma vez que também encontramos dois grupos de projetos entre os usuários mais fracos. ¿Podemos dizer, porém, que o uso da ferramenta fortaleceu a coesão e estruturação do grupo e promoveu o trabalho colaborativo?

Durante as entrevistas, para todas as questões que procuraram evidenciar o papel da ferramenta na organização do trabalho, na tomada de iniciativas, na produção de novas ideias, etc., as respostas enfatizaram que, nestes pontos, as coisas estavam quando foi instalado em paralelo e o uso da ferramenta, e ainda apoiou e promoveu treinamentos colaborativos.

Depois, tudo acontece como se no final acontecesse o contrário, com grupos bem estruturados que apoiam favoravelmente a ferramenta e, com as suas práticas colaborativas sólidas, tirando o máximo partido do seu uso. Sem dúvida, isso fortalece ainda mais sua capacidade de trabalhar coletivamente em um processo iterativo entre ferramenta e grupo a serviço do desenvolvimento coletivo. Ao contrário, e os grupos que pouco utilizaram a ferramenta? Podemos dizer simetricamente que esse baixo uso anda de mãos dadas com uma colaboração mais difícil?

Se nos atermos à observação, isto é, levando em consideração apenas os indicadores quantitativos, ficaríamos tentados a responder afirmativamente, pois a maioria dos usuários fracos testemunhou um funcionamento coletivo menos harmonioso, em termos dos componentes indicados. Mas pelo menos um dos grupos fornece um contra-exemplo: a ferramenta não foi usada enquanto o treinamento colaborativo parecia estar bem estabelecido. 
Seja o uso fraco ou forte, é claro que, se houver correlação entre o uso da ferramenta e o desempenho do equipamento, é sempre o desempenho do equipamento que prevalece e aquele que induz ou não induz o uso, segundo um conjunto de parâmetros bastante complexos, como mostram as entrevistas. Seja pela natureza do trabalho a ser realizado, pelo tamanho do grupo, pela facilidade de uso ou apropriação da ferramenta em ambientes pessoais de trabalho, pelo papel proativo do tutor ou de alguns membros do grupo, pela confiança e fluidez das comunicações, em última instância são os grupos que têm o controle dos ratos, e que uma ferramenta comum disponível se tornará um verdadeiro espaço compartilhado facilitando a realização do trabalho.

Avaliamos o treinamento colaborativo quanto ao uso da ferramenta? Portanto, parece difícil, diante desses resultados, considerar que indicadores como o número de contribuições, a taxa de estruturação, etc., sejam por si só ferramentas confiáveis para avaliar a formação colaborativa, pelo menos no quadro dos sistemas observados neste estudo, que pode ser diferente com ensino puramente a distância, onde nossos três componentes são totalmente carregados pelas ferramentas. No entanto, esses dados quantitativos indicam uma tendência. Mas para ir mais longe, eles devem ser completados com uma análise mais detalhada dos rastros (versões sucessivas de um documento; ligação entre partes de documentos e documento final; distribuição de contribuições ao longo do tempo; interrelações entre contribuições em diferentes funcionalidades, etc.) e compare-os com o que os atores dizem.

$\mathrm{Na}$ verdade, o que as entrevistas indicam, de forma mais ou menos sustentada, é efetivamente esse trabalho de articulação, e onde esse trabalho adicional é necessário para que o esforço coletivo de uma equipe seja, em última instância, mais do que um esforço caótico de dispersão. (citado por Michèle Lacoste, em Borzeix 2001). Portanto, podemos fazer a pergunta sobre a ferramenta em outras palavras.

Contribuição da ferramenta para o treinamento colaborativo? Quando propusemos uma série de verbos ao final de nossas entrevistas para avaliar o papel da ferramenta, nossos entrevistados colocaram o termo share na primeira posição, mas o de conservar retornou quantitativamente com mais frequência (quando vários verbos foram mencionados). Durante as discussões foram evocadas representações pertencentes ao mesmo campo semântico: local de armazenamento, centro de arquivo, local de arquivo, biblioteca de arquivo. No entanto, a partir da análise dos rastros e do que os grupos entrevistados nos contaram, parece que essa questão da conservação precisa ser tratada com maior precisão. Entre o local de armazenamento e o local de conservação, o espaço parece-nos apropriado de forma diferente em termos de reaproveitamento. 
Preservar implica a ideia de uma memória, de algo que acabará por participar da atividade e para o qual é necessário algum esforço, enquanto o armazenamento parece ser um lugar morto onde se acumulam documentos frios. Portanto, manter uma ferramenta de treinamento colaborativo não é apenas colocar em um lugar separado, mas acima de tudo tornar visíveis os documentos comuns. Vimos em que medida esses documentos, em seu processo, foram objeto de trabalho editorial por meio de sucessivas correções e validações (colocamos apenas documentos limpos no espaço).

O espaço mostra também este trabalho editorial de quem vai ordenar, selecionar e organizar os documentos, é lançada uma gestão completa da visibilidade. Além disso, é um ponto cego em nosso trabalho ter que lidar apenas com as cópias restantes após os arquivistas terem procedido à limpeza dos espaços, às vezes eliminando todos os documentos intermediários (e ao mesmo tempo os testemunhos de uma participação do espaço em trabalho em andamento) para determinados grupos.

Essa noção de visibilidade que um de nossos entrevistados traduziu pelo termo panóptico reflete o desejo de controlar, à medida que avançamos, o que foi construído coletivamente. É possível que estejamos aqui, mas isso será objeto de um aprofundamento desta pesquisa, a noção de cognição distribuída de Hutchins, onde a memória da informação está presente tanto nos indivíduos quanto nos instrumentos de trabalho, nas sinergias do grupo. (citado por Grosjean e Lacoste, 1999).

É com essa condição que pode surgir a inteligência coletiva, e não é incomum que todo o grupo de beneficiados expresse com palavras esse trabalho de construção: É difícil, trabalho de grupo. Você tem que lidar com diferentes personalidades. Nem sempre estamos certos. Então, às vezes, dizemos a nós mesmos que estávamos coletivamente certos. Juntando-se aí Bagnara, Rizzo e Failla ((citado por Grosjean e Lacoste, 1999), a quem deixaremos o cuidado de encerrar esta apresentação: $O$ conhecimento não é considerado como uma ação ou como um mercado onde todos estão, mas são construídos como ação comum, trocas e conflitos, e a contribuição cotidiana para uma mesma organização. 


\section{Referências}

Afnor (2004) BP Z76-001 Tecnologia da informação, treinamento aberto e a distância: repositório de boas práticas.

Arnaud M., Gebers E. (2004), Padrões e monitoramento das atividades dos alunos por meio de padrões de e-learning. Distâncias e sabores, volume $2 \mathrm{n}^{\circ} 4$.

Cardon D., (1997), The social sciences and machines to cooperate. Uma aproximação bibliográfica do CSCW, Réseaux, Cnet, $\mathrm{N}^{\circ} 85$.

Deaudelin, C., Nault Thérèse (2003), Colaborando para aprender e fazendo as pessoas aprenderem: o lugar das ferramentas tecnológicas. Prensas da Universidade de Quebec, Sainte - Foy.

Dillenbourg P. (1999) O que você entende por aprendizagem colaborativa? Em P. Dillenbourg (Ed) Aprendizagem colaborativa: abordagens cognitivas e computacionais. Elsevier.

Gaulmyn MM, Bouchard R. \& Rabatel A. (2001) O processo editorial. Escreva em várias vozes, Paris.

Grosjean M., Lacoste M. (1999), Comunicação e inteligência coletiva. Poof, Paris, Trabalho humano.

Guyot B., Peyrelong MF, AS (2005), Documento e organização. Relatório final.

Jermann P., Dillenbourg P. (1999), Uma análise dos argumentos dos alunos em um ambiente de aprendizagem coletiva, Suporte computacional para aprendizagem colaborativa.

Leplat J. (1991), Atividades coletivas e novas tecnologias, International Journal of Social Psychology, vol.4, $\mathrm{n}^{\circ} 34$.

Peyrelong MF, Follet M. (2004) O tutor, entre escritos e sussurros. ISDM n ${ }^{\circ} 18$.

Tricot, A., Plégat-Soutjis F. (2003). Utilidade, Usabilidade, Aceitabilidade: Interpretação das relações entre três dimensões da avaliação. Em C. Desmoulins, P. Marquet e D. Bouhinea. Ambientes computacionais para aprendizagem humana. Paris. 